\title{
Thoracolumbar fascia in children with hemiparesis: analysis of two cases
}

Keywords: fascia, children, hemiparesis, cerebral palsy

\section{Abbreviations: TLF, thoracolumbar fascia; CP, cerebral palsy \\ Background}

Hemiparesis is one of the possible topographic compromises in cerebral palsy, being spasticity in the hemibody its main characteristic. ${ }^{1,2}$ The increase of the mechanical tension can influence the structural, functional and biochemical fascia composition. ${ }^{3}$ Now, the thoracolumbar fascia (TLF) is the interface that connects the lower limb with the upper limb contralateral, giving an important role in walking, ${ }^{4}$ breathing, ${ }^{5}$ stabilization of the spine ${ }^{5,6}$ and load transfer. ${ }^{7-11}$ However, studies that have reviewed the characteristics of TLF in children with hemiparesis are non-existent.

\section{Objective}

To describe the structural characteristics of TLF in children with hemiparesis.

\section{Methodology}

Ultrasound was taken of the TLFs from both the apparently healthy and the affected side in 2 children (as), aged 8 and 10 years old, through the Philips iU22 device with a linear transducer located at $2 \mathrm{~cm}$ from the spinous process L2. Two variables were analyzed: thickness and echogenicity of the fascia. The study was approved by the ethics committee of the Faculty of Medicine of the National University of Colombia.

\section{Results}

A variation in the thickness of the TLF of $67.96 \%$ and $34.32 \%$ was observed in the hemibodies of the participants, speaking of a possible fibrosis comparing the hemibodies, which may suggest a cause or consequence of the use or disuse of the same. ${ }^{12}$ Likewise, there is a variation in the loose connective tissue, with a tendency to densify the TLF in two of the four intakes, which means a lower slippage of the fascial layers. ${ }^{13}$ The echogenicity of the TLF showed a hyperechoic layer generating between homogeneous and heterogeneous ecotextures, which could correspond to infiltrations of the loose or adipose connective tissue in the TLF. ${ }^{14}$

\section{Conclusion}

Ultrasound is a tool that allows to evaluate and diagnose the fascia, highlighting that the fascial system is involved in an integral movement distributed in myofascial chains, allowing ultrasound an approach to the tissue; therefore it complements the skill of the professional in the assessment of the individual. ${ }^{4}$

In children with hemiparesis, the structural characteristics of TLF are compromised in three of the four takings, which generate an antecedent to contemplate an integral view of the subject and a program with new alternatives strategies of intervention for children with cerebral palsy. The neuropediatric physiotherapy can benefit from the results provided by the ultrasound analysis in future studies
Volume 4 Issue 5 - 2019

\begin{abstract}
Aydee Luisa Robayo Torres,' Katherin Julieth Gonzalez Lopez ${ }^{2}$

'Associate Professor, Department of Human Body Movement, Faculty of Medicine, National University of Colombia, Colombia ${ }^{2}$ Physiotherapist, National University of Colombia, Colombia
\end{abstract}

Correspondence: OAydee Luisa Robayo Torres, Associate Professor, Department of Human Body Movement, Faculty of Medicine, National University of Colombia, Colombia, Email alrobayot@unal.edu.co

Received: September 22, 2019 | Published: October II, 2019

in comparison of populations as well as the change of the fascia before an intervention in children with cerebral palsy.

\section{Implications}

In children with cerebral palsy, the dysfunction is an alteration of the central nervous system. ${ }^{15,16}$ Its evaluation and intervention involves an integral view that necessarily includes the fascial system, because it is a neurotransmitter, piezoelectric and tensegrite interface, so physiotherapy plays a vital card in the interaction of the child with cerebral palsy when including the fascial system..$^{17,18}$

This is a pioneer study not only for involving the assessment and possible diagnosis of the fascia through ultrasound, but also because of its use in the pediatric population, since from our understanding there are no other studies about the evaluation of the TLF in the population pediatric.

\section{Acknowledgement}

None.

\section{Conflicts of interest}

The authors declare that there is no conflict of interest.

\section{References}

1. Agarwal A, Verma I. Cerebral palsy in children: An overview. J Clin Orthop Trauma. 2012;3(2):77-81.

2. Bobath B. Hemiplejia del adulto. Tercera. Argentina; 1993.

3. Drewes E, Driscoll M, Blyum L, Vincentz D. The Effects of a Home-Based Connective Tissue Targeting Therapy on Hip Development in Children With Cerebral Palsy: Six Case Reports. Explore (NY). 2016;12(4):268276.

4. Myers T. Anatomy trains. myofascial meridians for manual and movement therapist. Second Edi. 2009.

5. Willard FH, Vleeming A, Schuenke MD, et al. The thoracolumbar fascia: Anatomy, function and clinical considerations. J Anat. 2012;221(6):507536 . 
6. Wong K, Chai H, Chen Y, et al. Musculoskeletal Science and practice mechanical deformation of posterior thoracolumbar fascia after myofascia release in healthy men: A study of dynamic ultrasound imaging. Musculoskelet Sci Pract. 2017;27:124-130.

7. Griefahn A, Oehlmann J, Zalpour C, et al. Do exercises with the foam roll short impact on the thoracolumbar fascia? A randomized, controlled trial. J Bodyw Mov Ther, 2015;19(4):671.

8. Huijing PA. Epimuscular myofascial force transmission between antagonistic and synergistic muscles can explain movement limitation in spastic paresis. J Electromyogr Kinesiol. 2007;17:708-724.

9. Szopa A. Postural orientation and standing postural alignment in ambulant children with bilateral cerebral palsy. Clinical Biomechanics. 2017;49(August):22-27.

10. Bordoni B, Zanier E. Anatomic connections of the diaphragm: influence of respiration on the body system. J Multidiscip Healthc. 2013;25(6):281291.

11. Langevin HM, Fox JR, Koptiuch C, et al. Reduced thoracolumbar fascia shear strain in human chronic low back pain. BMC Musculoskelet Disord. $2011 ; 12$.
12. Luomala T, Pihlman M, Heiskanen J, et al. Case study: Could ultrasound and elastography visualized densified areas inside the deep fascia?. $J$ Bodyw Mov Ther. 2014;18(3):462-468.

13. Pavan PG, Stecco A, Stern R, et al. Painful connections: densification versus fibrosis of fascia. Curr Pain Headache Rep. 2014;18(8).

14. Daniels J, Dexter W. Basics of musculoskeletal ultrasound. Primera. New york; 2013.

15. Barber L, Barrett R, Lichtwark G. Passive muscle mechanical properties of the medial gastrocnemius in young adults with spastic cerebral palsy. $J$ Biomech. 2011;44(13):2496-2500.

16. Smith LR, Lee KS, Ward SR, et al. Hamstring contractures in children with spastic cerebral palsy result from a stiffer extracellular matrix and increased in vivo sarcomere length. J Physiol. 2011;589(10):2625-2639.

17. Palsy C, Pain A, Therapist P, et al. The effects of osteopathic treatment on constipation in children with cerebral palsy: a pilot study. J Manipulative Physiol Ther. 2009;32(8):648-653.

18. Diwan SJ, Bansal AB, Chovatiya H, et al. Effect of anterior chest wall myofascial release on thoracic expansion in children with spastic cerebral palsy. Int J Contemp Pediatr. 2014;1(2):94-99. 